\title{
CFD Study of Heat Transfer Reduction Using Multiple Injectors in a DCEE concept
}

\author{
Author, co-author (Do NOT enter this information. It will be pulled from participant tab in \\ MyTechZone) \\ Affiliation (Do NOT enter this information. It will be pulled from participant tab in MyTechZone)
}

\begin{abstract}
Earlier studies on efficiency improvement in CI engines have suggested that heat transfer losses contribute largely to the total energy losses. Fuel impingement on the cylinder walls is typically associated with high heat transfer. This study proposes a two-injector concept to reduce heat losses and thereby improve efficiency. The two injectors are placed at the rim of the bowl to change the spray pattern. Computational simulations based on the Reynolds-Averaged Navier-Stokes approach have been performed for four different fuel injection timings in order to quantify the reduction in heat losses for the proposed concept. Two-injector concepts were compared to reference cases using only one centrally mounted injector. All simulations were performed in a double compression expansion engine (DCEE) concept using the Volvo D13 single-cylinder engine. In the DCEE, a large portion of the exhaust energy is re-used in the second expansion, thus increasing the thermodynamic efficiency. To isolate the heat losses associated with the changed spray pattern of the two-injector concept, effects of the heat release are excluded during the analysis. Results showed that the optimal injection strategy allows a decrease in the temperature close to the walls, leading to heat loss reduction up to $13 \%$ or $2 \%$ of the fuel energy. The residual exhaust energy was increased by $1.5 \%$-points with the twoinjector concept when compared to the reference case. This proved the advantage of the two-injector concept compared to conventional single injector case for the DCEE application.
\end{abstract}

\section{Introduction}

Increasing the efficiency of the internal combustion engines becomes gradually more critical to meet the global efforts of $\mathrm{CO}_{2}$ emissions reduction and achieve energy sustainability. Toward this goal, EU has set a target to reach $15 \% \mathrm{CO}_{2}$ reduction for heavy duty vehicles by 2025 and $30 \%$ reduction until 2030 [1].

In the heavy-duty engine applications, one promising approach is the double compression expansion engine (DCEE) [2]. This concept divides the standard cylinder into four parts (see Figure 1), namely the high-pressure (HP) cylinder, the low-pressure (LP) cylinder, and the two cross-over tanks. The LP-cylinder compresses the air before transferring it to the HP-cylinder where a second compression takes place, thus effectively achieving an extremely high-pressure condition, at which fuel injection and combustion occur at nearly isobaric conditions.

Page 1 of 12
By dividing the four strokes into two cylinders, a high compression ratio can be used without the typical drawback of escalating friction losses. Based on this concept, Lam et al. [3, 4] reported up to $52.7 \%$ brake thermal efficiency for different engine operating conditions. Further efficiency improvement has been demonstrated for the DCEE concept by Shankar et al. [5] with the use of insulation to reduce the heat transfer losses.

The HP-cylinder will not expand the gases fully, but part of the energy will be transferred to the LP-cylinder for a second expansion. Consequently, it is beneficial to have a higher exhaust gas temperature and so, higher residual exhaust energy. Thus, it becomes particularly important to minimize the heat transfer through the cylinder walls (liner, piston, and head).

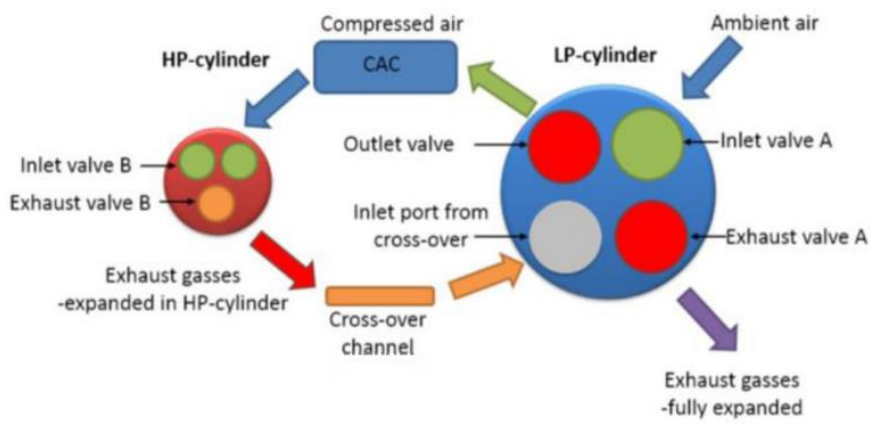

Figure 1, DCEE concept described graphically [3]

Heat losses have been a most common source of efficiency losses for general engine applications, and thus some approaches for heat transfer reduction have been suggested. One popular research topic today is the low-temperature combustion concepts including partially premixed combustion (PPC) [6] and homogeneous charge compression ignition (HCCI) [7]. In these engines, a lower mean temperature of the cylinder gases is used to reduce the heat transfer losses. For the PPC concept, a study [8] is performed at different load conditions obtaining $57 \%$ indicated efficiency. Claims of low heat transfer losses as well as low exhaust losses were presented.

However, using this concept the bulk temperature will also be low, implying difficulties in high load operations. HCCI is more homogenous than PPC through its early injection, and a previous study [7] claimed that the low bulk temperature gives a lower heat transfer through the walls. However, other studies [9] have notified the difficulty of ignition and low combustion efficiency for HCCI. As such, a lower heat transfer does not always lead to higher efficiency. 
In general, a lower mean temperature corresponds to smaller temperature differences between the cylinder wall and fluid so that a lower heat flux follows. Accordingly, keeping the high-temperature zones away from the walls after the combustion process will reduce heat transfer losses.

In a typical heavy duty (HD) diesel engine, reduction of heat loss is achieved by preventing the wall-impingement of sprays when using a centrally mounted injector. Sprays directed towards the cylinder walls push the hot temperature zones close to the boundary. A few solutions to this problem are a reduction of injection pressure and longer injection duration to reduce the spray penetration length. However, there is a limit for these solutions when a high load is needed since more fuel has to be injected. Another solution was suggested by Uchida et al. [10] using a new concept with multiple injectors. Following this approach, the primary objective of the present study is to assess the level of heat loss reduction by multiple injection strategies.

When using two injectors directed at different angles, the distance between the injector and the wall is increased for the same amount of fuel injected, thus allowing a reduced spray wall impingement. Therefore, it is of interest to investigate how much gain in heat loss reduction can be achieved considering the increased cost from multiple injectors. In this study, the reduction of heat loss for a twoinjector concept is quantified, and the actual efficiency gain is reported. It is shown that lower heat transfer losses result from the changed spray pattern compared to other physical effects, thereby demonstrating the feasibility of the two injector strategies in highefficiency engines.

\section{Method}

Three-dimensional RANS CFD simulations have been completed using the software Converge (version 2.4) during the compression stroke and expansion stroke of the high-pressure unit. No air exchange and pumping losses have been taken into account in this study.

\section{CFD Setup}

Only the combustion chamber has been chosen as the computational domain in this study, i.e., valves, intake and exhaust systems have not been considered. In order to compensate this, the chamber has been assumed to contain a specified composition of gases at the start of compression. The leftover exhaust gases from the previous cycle in this composition have been assumed to contain only water, carbon dioxide $\left(\mathrm{CO}_{2}\right)$, nitrogen $\left(\mathrm{N}_{2}\right)$ and oxygen $\left(\mathrm{O}_{2}\right)$ since these are normally the main components in diesel engine exhaust. Since intake flow is not considered in this setup, an initial turbulence level was set.

The geometry studied here is a standard 4-stroke Volvo D13 engine but with an altered compression ratio (see Table 1). A constant engine speed of $1200 \mathrm{rpm}$ was used for all different cases in order to compare the different injector setups independent of engine speed. All cases were simulated using diesel as fuel, injected at different times. Only the fluid domain was simulated, and wall temperatures were assumed constant.

Page 2 of 12
Table 1, Engine Parameters

\begin{tabular}{|l|l|}
\hline Engine parameters & \\
\hline Cylinder volume & 2.331 \\
\hline Stroke & $158 \mathrm{~mm}$ \\
\hline Bore & $131 \mathrm{~mm}$ \\
\hline Connecting Rod & $267.5 \mathrm{~mm}$ \\
\hline Compression Ratio & $11.5: 1$ \\
\hline Engine Speed & $1200 \mathrm{rpm}$ \\
\hline Intake Temperature & $464.15 \mathrm{~K}$ \\
\hline Nozzle hole diameter & $240 \mu \mathrm{m}$ \\
\hline Number of injector holes & 6 \\
\hline Standard umbrella angle & 145 degrees \\
\hline Lambda & 3.2 \\
\hline Intake Pressure & 5 bar \\
\hline
\end{tabular}

\section{Spray Model Setup}

Since diesel consists of many different components, the fuel is assumed to be $n$-heptane after evaporation but with the lower heating value of diesel. The physical properties of $n$-heptane are incorporated in the CFD code. KH-RT [11] spray breakup model was used to represent the spray injection, where it is assumed that the droplets merge and disperse during the breakup process. Moreover, all droplets were assumed spherical, and the Frossling droplet evaporation correlation [12] was used to calculate new droplet diameter during evaporation. The Rosslin-Rammler cumulative probability distribution was implemented to account for the size distribution of droplets in the domain.

Here, a renormalized group k-epsilon RANS turbulence model was used to account for in-cylinder turbulence. Other physical sub-models follow the standard built-in capabilities in CONVERGE v2.4 [13].

Regarding the mesh, a base grid size of $2 \mathrm{~mm}$ was used in all three directions. A fixed embedding per injector was added to account for the near-nozzle flow. The flow inside nozzles is not considered in the study. Level 3 adaptive mesh refinement (AMR) was used based on velocity and temperature gradients inside the combustion domain. The resulting minimum cell size in each direction becomes $2 / 2^{3}=0.125$ $\mathrm{mm}$. The mesh strategy is in general based on previous CFD studies in a CI engine [14].

All heat transfer calculations are using the O'Rourke heat transfer model [15] based on the law of the wall where a constant wall temperature of $500 \mathrm{~K}$ is assumed. Note that heat transfer calculations are not validated for this specific engine and should only be seen as approximate. However, the models are commonly used and assumed to give a relevant picture, if yet not exact, of the actual heat transfer. 


\section{Chemistry}

The chemical models are an essential part of any engine combustion simulation in order to get the ignition delay as well as combustion timing correct. A SAGE multi-zone combustion model [16] was used by mapping the grid cells to the temperature bins of $5 \mathrm{~K}$ and equivalence ratio bins of 0.05 increments.

The mechanism used is a skeletal n-heptane mechanism [17] with 110 species, which has been proven to work at a number of different operating conditions.

\section{Validation}

Since many simplifications and assumptions are needed for RANS CFD simulations, a validation process has been performed based on the setup discussed above. Simulation results have been compared to experiments conducted at the combustion engines group at Lund University [18].

The compression ratio was first adjusted by comparing the motored cases containing only air at the start of compression. From this, it could be established that the effective compression ratio is 11.41 instead of 11.5. This is reasonable since connecting rod flex makes the effective compression ratio lower [19] which is not taken into account by the CFD models

With the compression ratio set, leftover exhaust gases were introduced in the chamber. These were assumed only to contain water, $\mathrm{CO}_{2}, \mathrm{~N}_{2}$ and $\mathrm{O}_{2}$ since these are the major components. Leftover residual gases are expected to be present from the previous cycle due to gas exchange inefficiencies. This has an effect on the fluid specific heat ratio, which was decided through comparison with the experimental data before the start of combustion.

The injection timing of the fuel was varied from 1 CAD BTDC to 0.2 CAD BTDC to account for the delay time from signal until actual injector pressure is built up. Similarly, for the end of injection, the duration was altered from 7.2 CAD to 8.5 CAD to account for the delay in closing. Ignition delay was optimized to fit experimental results.

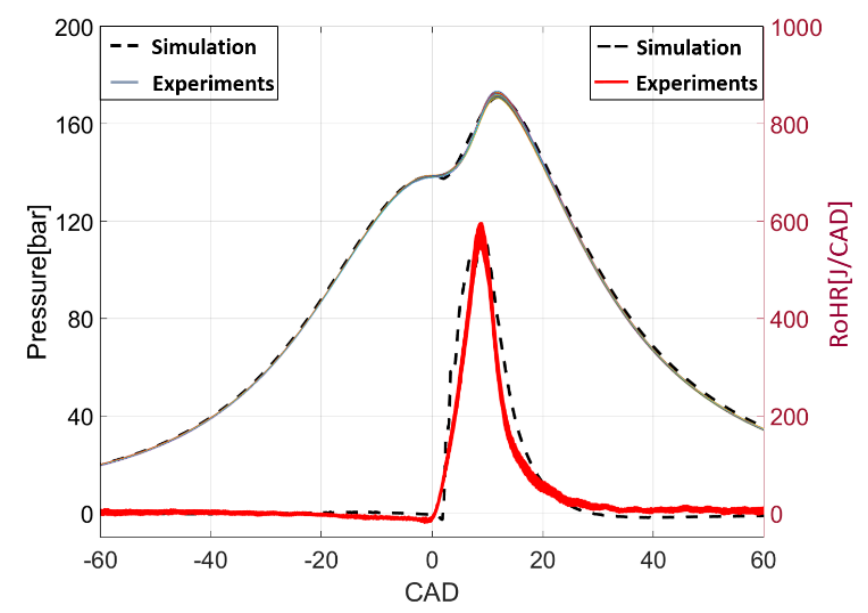

Figure 2, Pressure [bar] and RoHR [J/CAD] traces of the simulation case vs. experimental results

Page 3 of 12
With these adjustments, a good fit of the pressure trace could be achieved with respect to experimental results (see Figure 2). Furthermore, the RoHR plot shows that the simulation is slightly over-predicting the amount of heat released at the start of combustion. However, this will not impact the heat transfer through the walls much, which is the main topic of this study.

Pressure, RoHR and ignition delay matched experimental data well with only minor perturbations. Thus, the models were considered validated. This case was the base for the final setup used in this study. Heat transfer models were assumed to be validated since no extreme measures were required to achieve the decent fit of the simulation case.

\section{Project Approach}

To understand how multiple injectors can reduce heat transfer losses, a number of cases were tested. The cases were divided into two groups, reference cases, and two-injector cases. Two injectors were decided with the knowledge that more injectors will be challenging and costly to fit in a real engine application. Different injection timings were used in order to investigate the impact of varied combustion phasing. This gives a relevant way of comparison between cases and excludes the possibility that a reduced heat transfer would only be an effect of a single combustion phasing.

Four different injection timings were tested to compare different values of IMEP. These times were chosen as the typical CI conditions $-7,-4,-1$ and 2 CAD ATDC. All cases have equal fuel amount, 150 mg per stroke or 32.78 bar FuelMEP, to be able to make a good comparison. The bowl geometry, which is a standard Volvo D13 geometry, can be seen in Figure 3. Here, the two injectors placed at the rim of the bowl are also shown.

For the two-injector cases the fuel amount was split equally between the outer injectors. This means the same injection velocity as the reference case with equal amount of injector holes. The injection is a single injection for all cases. Spray cone angles used for all injectors are 10 degrees.

Initial spray studies have been performed to find the optimum umbrella angle as well as other angles in terms of minimizing heat transfer for the two-injector cases. However, the angles used in the reference cases are standard Volvo D13 in order to compare with the real case. These angles are already optimized in terms of reducing the heat transfer losses. 


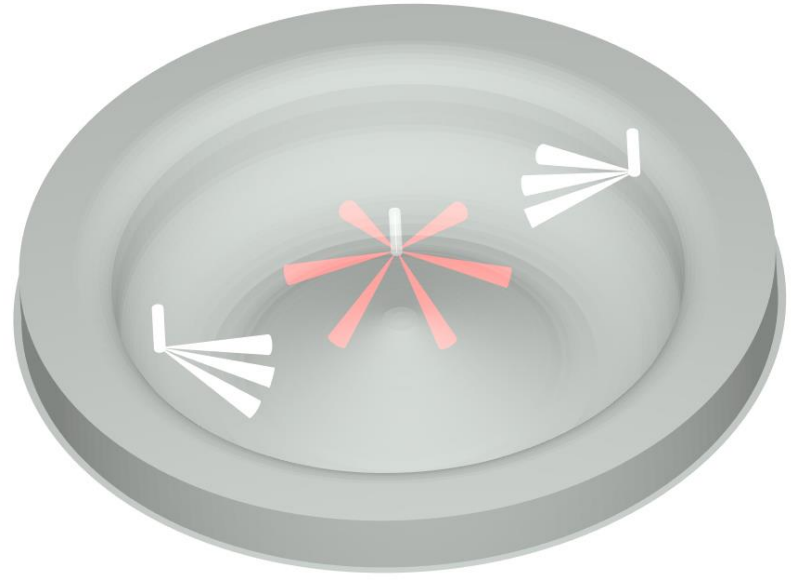

Figure 3, Bowl geometry at TDC with one central (red color) and two outer injectors (white color) mounted

More cases were tested, but only the most relevant ones are presented in this study due to space limitations. The lambda chosen, and so the fuel amount, is due to that this case was the one validated. Table 2 shows the final cases selected.

Table 2, Design of Experiment (DOE) with a sweep of injection timings

\begin{tabular}{|l|l|l|l|l|}
\hline & \multicolumn{3}{|l|}{ Injection timings [CAD ATDC] } \\
\hline $\begin{array}{l}\text { Cases, } \\
\text { reference and } \\
\text { two-injector }\end{array}$ & -7 & -4 & -1 & 2 \\
\hline
\end{tabular}

\section{Results}

This section emphasizes not only how heat transfer through the walls is reduced but also covers the reason for the reduction in heat transfer. Many parameters play an important role in the engine, and there is a need for investigating which ones are more dominant here. In this study, cylinder liner, piston and head boundaries are referred to as the cylinder wall.

\section{Reducing Heat Transfer Losses}

Heat transfer losses were in general found to be lower for the twoinjector cases. Figure 4 shows the total heat transfer losses, i.e., energy lost through the walls during compression and expansion strokes for the different cases. It also shows how much heat was lost through the piston, liner, and head individually where it is important to remember that the liner has a dynamic area throughout the stroke. It can be seen that for all injection timings the heat transfer losses were lower for the two-injector case compared to the reference case. The most significant difference can be found for an injection timing of 2 CAD ATDC with close to $13 \%$ (equal to $2 \%$ of the fuel energy) decrease in total heat transfer with the use of two injectors. On the contrary, the smallest difference of around $10 \%$ is found for injection timing of -7 CAD ATDC.

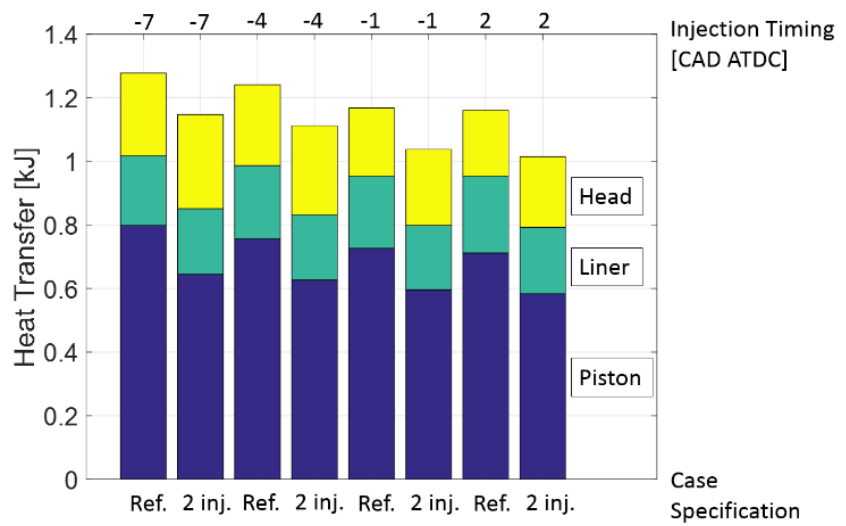

Figure 4, Total heat transfer from -180 to 180 CAD ATDC for the different cases. The bars are split up in heat transfer losses through piston, liner, and head

The main part of the heat transfer comes from the piston, which is expected since in general the sprays are directed towards the piston bowl. The liner area is small close to TDC, and the sprays are directed away from the cylinder head. Thus, the piston plays a more prominent role for heat transfer and will be considered more carefully in this study.

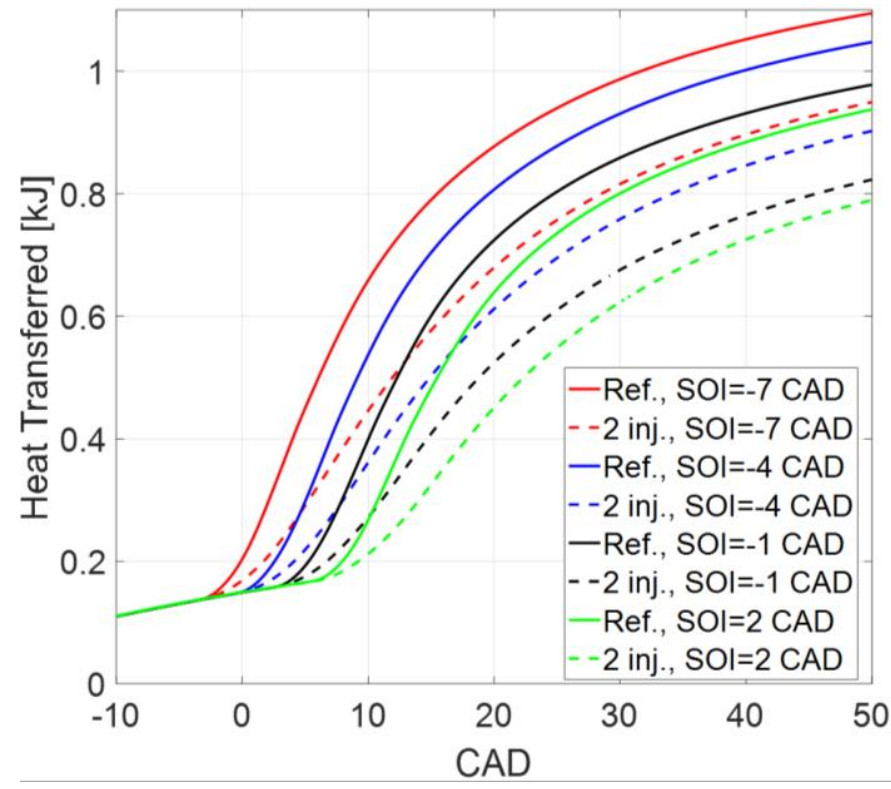

Figure 5, Heat transfer [kJ] vs. CAD for the different cases. The dashed line indicates cases using two injectors

Many different parameters will have an impact on heat transfer such as mean cylinder temperature and CA50 (CAD at which $50 \%$ of the heat is released). One such parameter is the time of heat transfer occurrence. Figure 5, Figure 6 and Figure 7 suggest that the most rapid rise in heat transfer occurs a few CAD after the start of combustion which is expected since the hot temperature gases take time to reach the wall. The rate of heat release (RoHR) is somewhat higher for the two-injector cases, but heat transfer rise rate is still lower. 


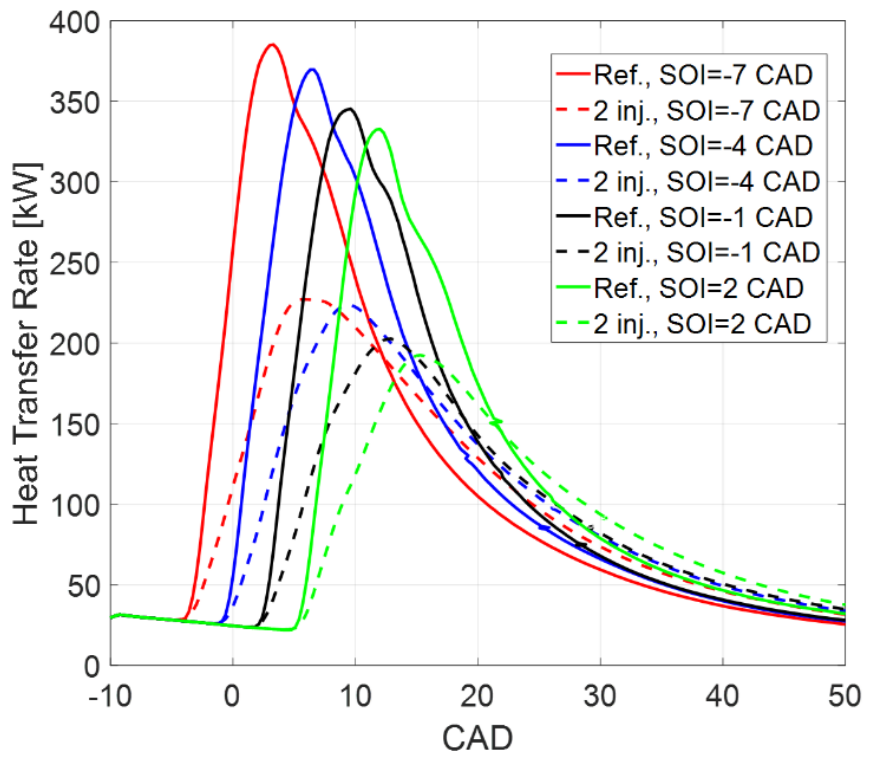

Figure 6, Heat transfer rate $[\mathrm{kW}]$ as a function of CAD for different cases. The dashed line indicates cases using two injectors

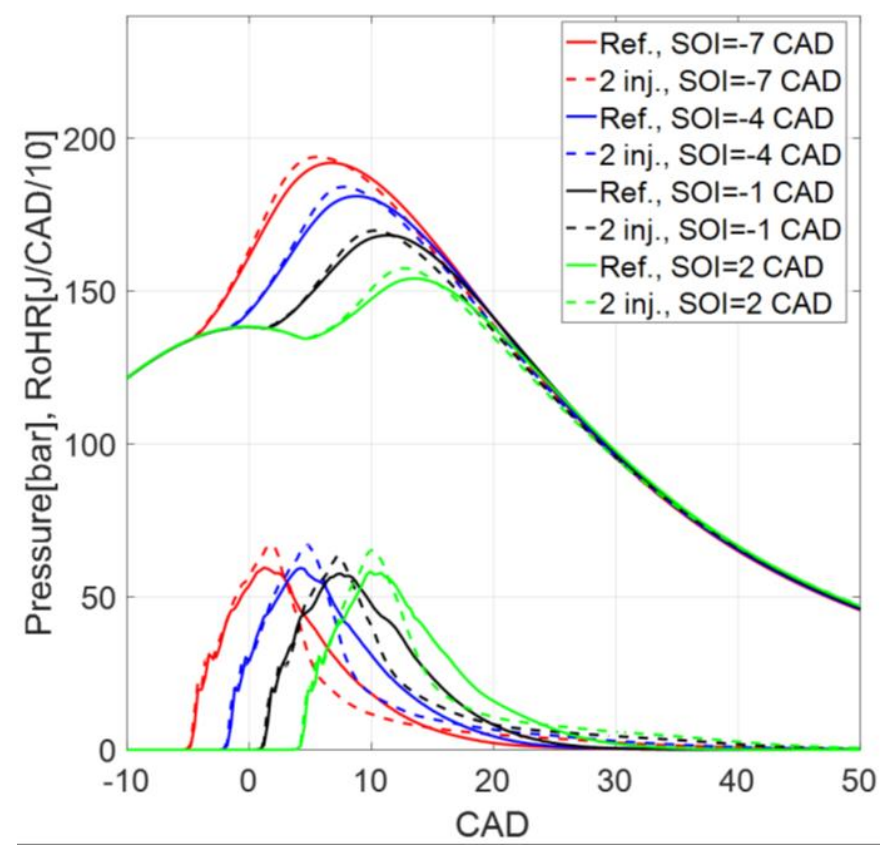

Figure 7, Pressure [bar] and rate of heat release [J/CAD] divided by ten as a function of CAD

Furthermore, a longer heat release tail can be seen for the twoinjector cases. This is associated with a higher heat transfer due to the longer exposure time of high mean temperature as well as the larger surface area [20]. However, this is not evident for cases reported herein where heat transfer is still reduced for the two-injector cases. Therefore, any judgments on heat transfer cannot be made based on heat release itself.

An essential factor for heat transfer losses is the CA50 due to its impact on mean cylinder temperature. For this study, the injection timing has been kept, and so the CA50 was relatively constant (see Figure 8) between two cases. This again proves that the heat release is not an explanation for the decreased heat transfer losses.

Page 5 of 12

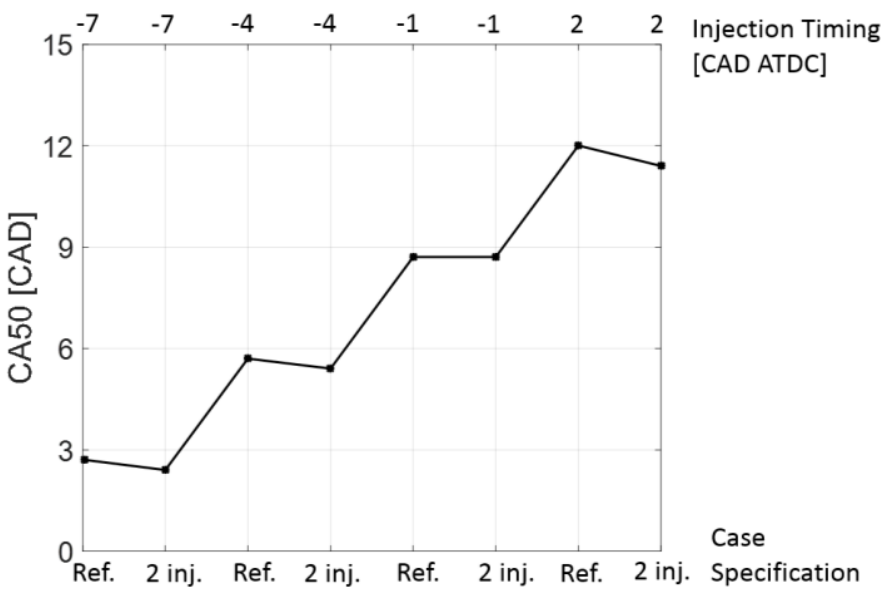

Figure 8, CA50 [CAD] for the different cases

The two injectors placed at the rim of the bowl are expected to show a different spray pattern compared to the reference case as discussed before. It is predicted that this spray pattern leads to less wall impingement since the injectors are placed further from the walls, giving longer distance before impingement occurs. Moreover, fuel is being sprayed in a swirling direction instead of straight towards the walls, further decreasing the wall-impingement. In order to investigate this, the wall area covered by hot temperature gases was investigated.

At first, the wall mean temperature for different cases is plotted and shown in Figure 9. The temperature of the fluid cells in the vicinity of the cylinder walls is arranged. For all injection timings, the peak mean wall temperature is significantly higher (up to $240 \mathrm{~K}$ ) for the reference cases compared to the two-injector cases. This shows that using multiple injectors reduces the heat transfer as wall impingement is decreased.

The fraction of fluid cells in the vicinity of the piston wall having a temperature higher than $1500 \mathrm{~K}$ (Figure 10) shows that the twoinjector cases have a significantly lower value compared to the reference geometry. As discussed earlier, the piston is the main contributor to heat transfer occurrence. A more significant part of the wall area has a higher temperature, which results in a higher temperature difference between wall and fluid. As an effect, higher heat transfer is naturally occurring.

The piston area covered by hot gases is also seen in Figure 11 where the reference case has a significantly larger area covered by hot gases. Here, only the cases for an SOI of -1 CAD ATDC were shown for illustration. While the reference case is showing very much impingement on the wall, the fuel injection into the swirling motion, as well as the increased distance to the wall, drags the hot gases away for the two-injector case. Thus, the changed spray pattern occurring from the use of multiple injectors is effective in keeping the hot temperature away from the cylinder walls. This effectively leads to reduced heat transfer and further efficiency gains can be achieved. As discussed before, one of the main benefits in the DCEE concept is that exhaust energy can be re-used in a second expansion. Without this feature, i.e. in a standard CI engine, this might not be as beneficial since the residual exhaust energy is just wasted. 


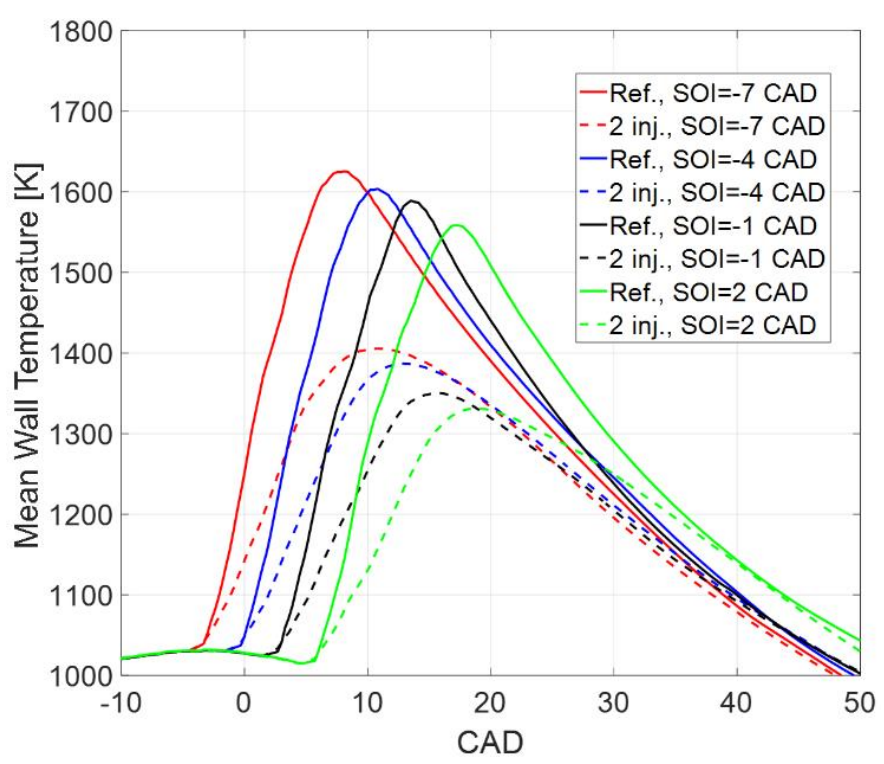

Figure 9, Mean wall temperature $[\mathrm{K}]$ as a function of $\mathrm{CAD}$ for the different cases

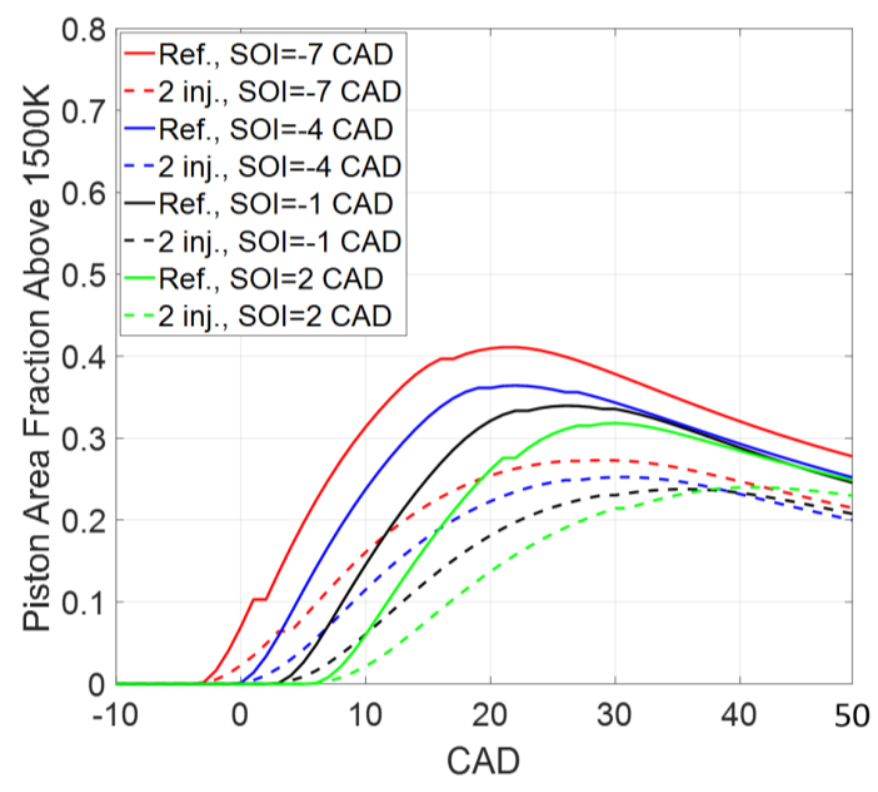

Figure 10, Piston wall area fraction having a temperature above $1500 \mathrm{~K}$

To get a view of how much energy gain is possible in the DCEE concept by using multiple injectors as introduced in this study, the exhaust energy was approximated and normalized by the displacement volume. Consequently, the exhaust mean effective pressure (EXMEP) can be decided for an assumed combustion efficiency of $100 \%$ since heat transfer is known.

Other MEPs and gross indicated efficiency were also calculated based on the formulations in Appendix A. From Table 3, it can be seen that the major benefit from multiple injectors is from the increased exhaust energy. IMEPs and so the indicated efficiencies are kept rather constant with a small increase for the two-injector case regarding IMEPg.

Page 6 of 12

\section{CAD ATDC, SOI=-1 CAD ATDC}

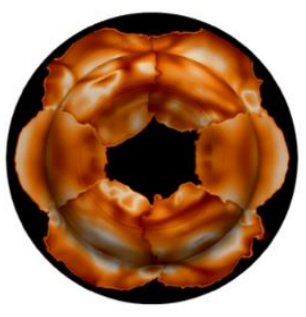

Ref. Case

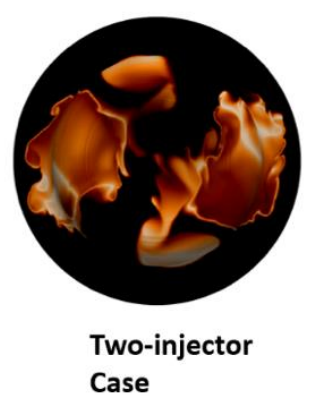

Case
- $2800 \mathrm{~K}$

$2600 \mathrm{~K}$

$2400 \mathrm{~K}$

$2200 \mathrm{~K}$ T [K]

$2000 \mathrm{~K}$

$1800 \mathrm{~K}$

$1600 \mathrm{~K}$

$1400 \mathrm{~K}$

Figure 11, Temperature surface of the piston wall at 12 CAD ATDC for the two different injector strategies at SOI=-1 CAD ATDC

The exhaust energy is, in fact, higher for all the two-injector cases compared to corresponding reference case (see Figure 12). In a normal diesel engine, this is less useful as the turbine efficiency is rather low. However, in the DCEE concept, this energy will be used for a second expansion and is therefore much desired.

The biggest difference can again be found for the injection timing of 2 CAD ATDC. Here the two-injector case has around $5 \%$ higher EXMEP compared to the reference case. This corresponds to around $1.5 \%$ of the fuel energy and indicates the gain in terms of efficiency that can be attained using multiple injectors.

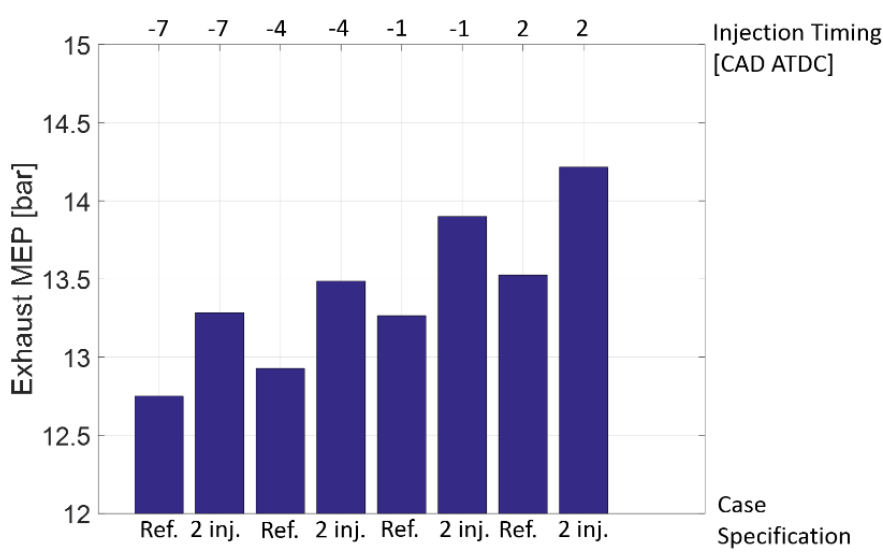

Figure 12, EXMEP [bar] for all cases

\begin{tabular}{|l|l|l|}
\hline Quantity & $\begin{array}{l}\text { Reference Case, } \\
\text { SOI = -4 CAD }\end{array}$ & $\begin{array}{l}\text { 2-injector Case, } \\
\text { SOI = -4 CAD }\end{array}$ \\
\hline FuelMEP & $32.78 \mathrm{bar}$ & $32.78 \mathrm{bar}$ \\
\hline HTMEP & $5.85 \mathrm{bar}$ & $5.22 \mathrm{bar}$ \\
\hline EXMEP & $12.93 \mathrm{bar}$ & $13.49 \mathrm{bar}$ \\
\hline IMEPg & $14.0 \mathrm{bar}$ & $14.05 \mathrm{bar}$ \\
\hline $\boldsymbol{\eta}_{\text {I_gross }}$ & $42.71 \%$ & $42.86 \%$ \\
\hline
\end{tabular}

Table 3, Mean effective pressures [bar] and efficiency for the reference and two-injector case at $\mathrm{SOI}=-4$. 
This results section concludes that the changed spray pattern occurring with the use of two injectors has a positive effect on heat transfer losses. It could be seen that this effect comes from the fact that a smaller amount of hot temperature zones were situated close to the cylinder walls. However, it should be noted that this study is not a fully optimized case but rather an investigation of how a typical case can be improved by using multiple injectors. This leaves space for future improvement of the multiple injector concepts.

\section{Conclusions}

CFD simulations were conducted to assess the level of heat loss reduction by employing two injectors in CI engines. While the DCEE engine application motivated the study, the two injector concept applies to general CI engine applications. The following conclusions are drawn from the results.

- Use of multiple injectors allows a reduction of heat losses by keeping hot temperature zones away from the cylinder walls

- Heat transfer reduction of up to $13 \%$ and $1.5 \%$ of the fuel energy savings was achieved by the use of two injectors placed at the rim of the bowl.

- Maximum mean wall temperature was reduced by up to $240 \mathrm{~K}$ for the two-injector case.

- Proper optimization of the spray parameters is found to be critical in achieving the maximum heat loss reduction.

\section{References}

1. European Commision, "Reducing $\mathrm{CO} 2$ emissions from heavyduty vehicles", https://ec.europa.eu/clima/policies/transport/vehicles/heavy_en (accessed 2018-05-10)

2. Bhavani Shankar, V., Lam, N., Andersson, A., and Johansson, B., "Optimum Heat Release Rates for a Double Compression Expansion (DCEE) Engine," SAE Technical Paper 2017-010636, 2017, doi:10.4271/2017-01-0636.

3. Lam, N., Tuner, M., Tunestal, P., Andersson, A. et al., "Double Compression Expansion Engine Concepts: A Path to High Efficiency," SAE Int. J. Engines 8(4):2015, doi:10.4271/201501-1260.

4. Lam, N., Andersson, A., and Tunestal, P., "Double Compression Expansion Engine Concepts: Efficiency Analysis over a Load Range," SAE Technical Paper 2018-01-0886, 2018, doi:10.4271/2018-01-0886.

5. Bhavani Shankar, V.S., Johansson, B., and Andersson, A., "Double Compression Expansion Engine: A Parametric Study on a High-Efficiency Engine Concept," SAE Technical Paper 2018-01-0890, 2018, doi:10.4271/2018-01-0890.

6. Noehre, C., Andersson, M., Johansson, B., and Hultqvist, A., "Characterization of Partially Premixed Combustion," SAE Technical Paper 2006-01-3412, 2006, https://doi.org/10.4271/2006-01-3412.

7. Caton JA. Comparisons of Global Heat Transfer Correlations for Conventional and High Efficiency Reciprocating Engines. ASME. Internal Combustion Engine Division Fall Technical Conference, ASME 2011 Internal Combustion Engine Division Fall Technical Conference ():327-337. doi:10.1115/ICEF201160017.

8. Manente, V., Johansson, B., Tunestal, P., and Cannella, W., "Effects of Different Type of Gasoline Fuels on Heavy Duty
Partially Premixed Combustion," SAE Int. J. Engines 2(2):7188, 2010, doi: 10.4271/2009-01-2668.

9. Sjöberg, M. and Dec, J., "Combined Effects of Fuel-Type and Engine Speed on Intake Temperature Requirements and Completeness of Bulk-Gas Reactions for HCCI Combustion," SAE Technical Paper 2003-01-3173, 2003, https://doi.org/10.4271/2003-01-3173.

10. Okamoto, T. and Uchida, N., "New Concept for Overcoming the Trade-Off between Thermal Efficiency, Each Loss and Exhaust Emissions in a Heavy Duty Diesel Engine," SAE Int. J. Engines 9(2):2016, doi:10.4271/2016-01-0729.

11. Reitz, R., and Diwakar, R., "Structure of High-Pressure Fuel Sprays," SAE Technical Paper $\underline{870598}$, 1987, doi:10.4271/870598.

12. Amsden, A. A., O'rourke, P. J., and Butler, T. D., KIVA-II: A computer program for chemically reactive flows with sprays (No. LA-11560-MS). Los Alamos National Lab., NM (USA), 1989.

13. Richards, K. J., Senecal, P. K., and Pomraning, E., "CONVERGE (Version 1.4.1) Manual," Convergent Science, Inc., Middleton, WI, 2012.

14. Sivasankaralingam, V., Raman, V., Mubarak Ali, M., Alfazazi, A. et al., "Experimental and Numerical Investigation of Ethanol/Diethyl Ether Mixtures in a CI Engine," SAE Technical Paper 2016-01-2180, 2016, doi:10.4271/2016-01-2180.

15. Amsden, A. A., "KIVA-3V: A Block Structured KIVA Program for Engines with Vertical or Canted Valves," Los Alamos National Laboratory Report No. LA-13313-MS, 1997.

16. Babajimopoulos, A., Assanis, D. N., Flowers, D. L., Aceves, S. M., et. al., "A fully coupled computational fluid dynamics and multi-zone model with detailed chemical kinetics for the simulation of premixed charge compression ignition engines," International journal of engine research, 6:497-512, 2005, doi:10.1243/146808705X30503.

17. Zeuch, Thomas, Gladys Moréac, Syed Sayeed Ahmed, and Fabian Mauss. "A comprehensive skeletal mechanism for the oxidation of n-heptane generated by chemistry-guided reduction." Combustion and Flame 155, no. 4 (2008): 651-674.

18. "Lam Nhut, Private Communication (2018)."

19. Aronsson, U., Solaka, H., Lequien, G., Andersson, O. et al., "Analysis of Errors in Heat Release Calculations Due to Distortion of the In-Cylinder Volume Trace from Mechanical Deformation in Optical Diesel Engines," SAE Int. J. Engines5(4):1561-1570, 2012, https://doi.org/10.4271/2012-01$\underline{1604 .}$

20. Sahoo P.K, Las L.M., "Combustion analysis of Jatropha, Karanja and Polanga based biodiesel as fuel in a diesel engine", Fuel V88, Issue 6, June 2009, Pages 994-999

21. Johansson Bengt et al, "Combustion engines, Volume 1", Lund University, 2014 
Abbreviations

ATDC

After top dead center

BDC

Bottom dead center

CA50

CAD

$\mathrm{CO}_{2}$

Cylinder Wall

DCEE

EXMEP

HCCI

IMEPg

IMEPn

$\mathbf{N}_{2}$

$\mathbf{0}_{2}$

PPC

RANS

RCCI

RoHR

SOI

TDC
Exhaust mean effective pressure

Crank angle degree at which $50 \%$ of the heat is released

Crank angle degrees

Carbon dioxide

Liner, piston and head boundaries

Double compression expansion engine

Homogenous charge compression ignition

Gross indicated mean effective pressure

Net indicated mean effective pressure

Nitrogen

Oxygen

Partially premixed combustion

Reynolds averaged Navier-Stokes

Reactivity controlled compression ignition

Rate of heat release

Start of injection

Top dead center

\section{Contact information}

Gustav Nyrenstedt

$\mathrm{Ph}$.D. Student

Clean Combustion Research Center (CCRC)

King Abdullah University of Science and Technology (KAUST)

23955-6900 Thuwal, Saudi Arabia

sven.nyrenstedt@kaust.edu.sa

Phone no - +966 (0)56 0458328

\section{Acknowledgments}

This work was sponsored by King Abdullah University of Science and Technology (KAUST). The simulations in this work were performed with the computing resources at the KAUST Supercomputing Laboratories. The authors would like to thank Dr. Georgios Markomanolis at KAUST Supercomputing Laboratory for helpful guidance in post-processing, Dr. Arne Andersson at Volvo Trucks Sweden for helpful comments, and Mr. Nhut Lam at Lund University for providing the experimental data for model validation. 


\section{Appendix}

\section{Appendix A- Definitions of Mean Effective Pressures and Engine Efficiencies}

The definitions of different mean effective pressures and efficiencies used in this study are in general based on Lam et al. [3] and Johansson et al [21] as follows in this appendix.

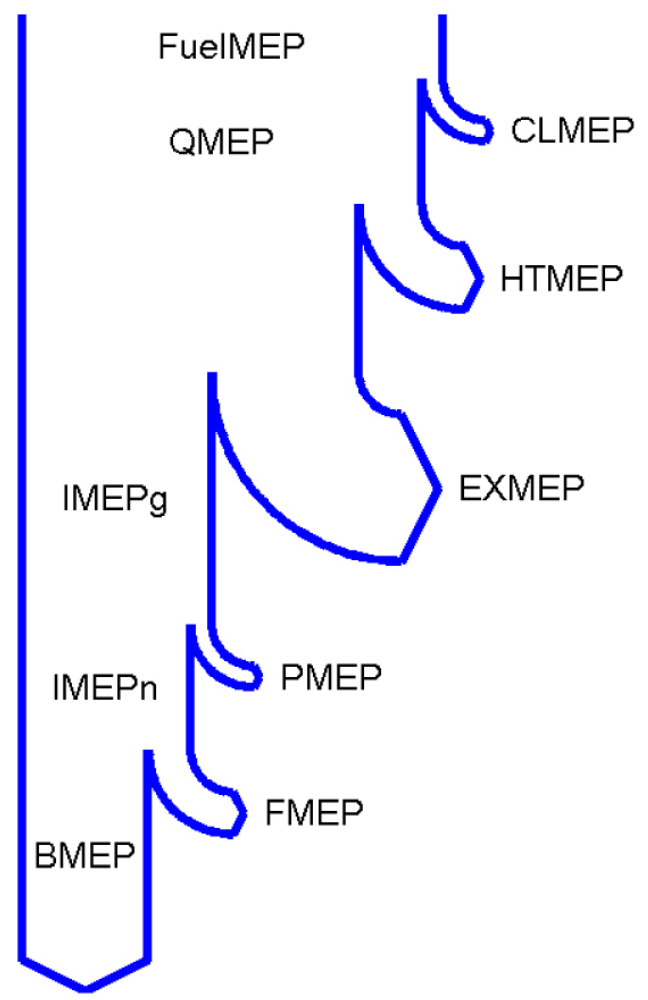

Figure A1. Sankey-diagram from the conversion of fuel energy to brake work,

\section{Fuel Mean Effective Pressure, FuelMEP}

This mean effective pressure represents the energy contained in the fuel supplied to the combustion chamber. It is simply energy content per mass unit of the fuel multiplied by the total fuel mass normalized by the displacement volume. We get

$$
\text { FuelMEP }=\frac{m_{f} * Q_{L H V}}{V_{D}}
$$

where

$$
\begin{aligned}
& \mathrm{mf}_{\mathrm{f}}=\text { mass of fuel per cycle }[\mathrm{kg}] \\
& \text { QLHV = Lower heating value of the fuel }[\mathrm{J} / \mathrm{kg}] \\
& \mathrm{V}_{\mathrm{D}}=\text { Displacement volume }\left[\mathrm{m}_{3}\right]
\end{aligned}
$$

\section{Heat Mean Effective Pressure, QMEP}

When combustion starts, the energy stored in the fuel is transformed into heat. The heat energy is expressed in Joules per cycle or if normalized by the displacement volume in the same way as for FuelMEP we get the heat mean effective pressure, QMEP as

$$
Q M E P=\frac{Q}{V_{D}}
$$

where

$\mathrm{Q}=$ amount of heat added per cycle $[\mathrm{J}]$

Page 9 of 12 
$\mathrm{V} D=$ displacement volume $\left[\mathrm{m}_{3}\right]$

\section{Gross Indicated Mean Effective Pressure, IMEPg}

The definition using only compression and expansion strokes is called gross indicated mean effective pressure, IMEPg

$$
I M E P_{g}=\frac{W_{E}+W_{C}}{V_{D}}=\frac{1}{V_{D}} \int_{0}^{360} p d V
$$

where the integration starts at $\mathrm{BDC}$ and ends at $\mathrm{BDC}+360 \mathrm{CAD}$ later.

The compression work is defined as:

$$
W_{C}=\int_{B D C}^{T D C} p d V
$$

And the expansion work is:

$$
W_{E}=\int_{T D C}^{B D C} p d V
$$

\section{Net Indicated Mean Effective Pressure, IMEPn}

The definition using all four strokes is called net indicated mean effective pressure, IMEP $\mathrm{n}$ and is thus expressed as

$$
I M E P_{g}=\frac{W_{E}+W_{C}+W_{\text {exhaust }}+W_{\text {intake }}}{V_{D}}=\frac{1}{V_{D}} \int_{0}^{720} p d V
$$

where we have added work for exhaust and intake strokes.

\section{Brake Mean Effective Pressure, BMEP}

BMEP is defined as the useful energy produced by the engine per cycle divided by the displacement volume as

$$
B M E P=\frac{W_{B}}{V_{D}}
$$

but it can also be expressed in terms of Power [W] per displacement and time as

$$
B M E P=\frac{P}{\frac{N}{n_{T}} * V_{D}}
$$

where

$$
\begin{aligned}
& \mathrm{P}=\text { Engine power }[\mathrm{W}] \\
& \mathrm{N}=\text { Engine speed }[\mathrm{rps}] \\
& \mathrm{nT}=\text { Stroke factor }[-] \\
& \mathrm{V}_{\mathrm{D}}=\text { Displacement Volume }\left[\mathrm{m}_{3}\right]
\end{aligned}
$$




\section{Combustion Loss Mean Effective Pressure, CLMEP}

The combustion losses can be expressed as a mean effective pressure as well. It is defined as

$$
\text { QemMEP }=\text { FuelMEP }-Q M E P
$$

\section{Heat Transfer Loss Mean Effective Pressure, HTMEP}

The heat transfer losses can be expressed as a mean effective pressure as

$$
H T M E P=\frac{Q_{H T}}{V_{D}}
$$

where

QHT= Heat transfer losses $[\mathrm{J}]$

\section{Exhaust Loss Mean Effective Pressure, EXMEP}

The exhaust losses can be expressed as a mean effective pressure as

$$
E X M E P=\frac{Q_{E X}}{V_{D}}
$$

where

$$
\text { QEX= Exhaust energy losses }[\mathrm{J}]
$$

\section{Pumping Loss Mean Effective Pressure, PMEP}

The pumping losses can be expressed as the difference between gross indicated mean effective pressure and net indicated mean effective pressure:

$$
P M E P=I M E P_{g}-I M E P_{n}
$$

\section{Friction Loss Mean Effective Pressure, FMEP}

The friction losses can be expressed as the difference between net indicated mean effective pressure and brake mean effective pressure:

$$
F M E P=I M E P_{n}-B M E P
$$

\section{Combustion Efficiency, $\eta \mathrm{C}$}

The combustion efficiency is how much heat that can be generated by the combustion of a fuel. It is defined as

$$
\eta_{C}=\frac{Q M E P}{\text { FuelMEP }}
$$

Thermodynamic Efficiency, $\eta \mathrm{T}$

The thermodynamic efficiency is defines as

$$
\eta_{T}=\frac{I M E P_{g}}{Q M E P}
$$

\section{Gas-Exchange Efficiency, $\eta \mathrm{GE}$}

$$
\eta_{G E}=\frac{I M E P_{n}}{I M E P_{g}}
$$


Mechanical Efficiency, ఇм

Mechanical efficiency is defined as

$$
\eta_{M}=\frac{B M E P}{I M E P_{n}}
$$

\section{Gross Indicated Efficiency, $\boldsymbol{\eta}_{I_{-} g r o s s}$}

Gross indicated efficiency is defined as

$$
\eta_{I_{-} \text {gross }}=\frac{I M E P_{g}}{\text { FuelMEP }}
$$

\section{Brake Efficiency, $\eta_{B}$}

Brake efficiency is defined as

$$
\eta_{B}=\frac{B M E P}{\text { FuelMEP }}
$$

